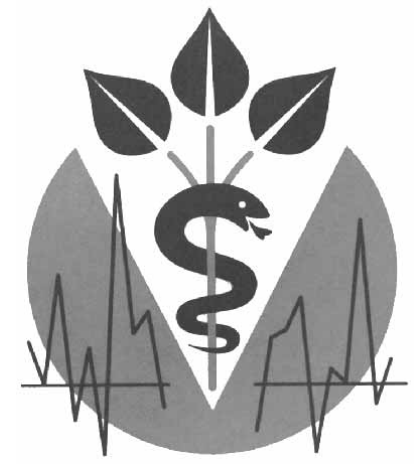

Karl und Veronica Carstens-Stiftung im Stifterverband für die Deutsche Wissenschaft Barkhovenallee 1 D-45239 Essen

Tel. +49 0201 8401-111, Fax -302

E-mail: m.fruehwald@stifterverband.de

\section{Berichte aus den Projekten}

Prof. Dr. A. Ogilvie, Institut für Biochemie; Dr. G. Steidl, Lehrstuhl für Technische Chemie I, Universität Erlangen

Zur Wirkung langkettiger Ozonide auf eukaryontische Zellen: Untersuchungen zum Mechanismus der Auslösung des programmierten Zelltodes (Apoptose)

Die Carstens-Stiftung fördert seit dem Jahr 1996 ein Projekt zu zellbiologischen Effekten von Ozoniden. Das Projekt wird gemeinschaftlich am Institut für Biochemie und am Lehrstuhl für Technische Chemie der Universität Erlangen durchgeführt. Erste Ergebnisse wurden bereits vorgestellt und sind ausserdem in den Jahrbüchern 3 und 4 der Carstens-Stiftung nachzulesen.

Mit einer wissenschaftlichen Erforschung der keimtötenden Eigenschaften von Ozoniden in Form von ozonisiertem Olivenöl wurde bereits in der 30er Jahren begonnen $[1,2]$. Später folgten klinische Berichte über den erfolgreichen Gebrauch von Ozoniden in der Dermatologie, z. B. für die Behandlung von Warzen, Hühneraugen, Psoriasis und Lichen planus [3].

In all diesen Fällen wurden die Ozonide äusserlich angewendet. Über eine Untersuchung zum innerlichen Gebrauch der Ozo-

\title{
Gesellschaftsmitteilungen · Society Bulletins
}

Forsch Komplementärmed 1999;6:337

nide wird bei Butz und La Lande [4] berichtet, die die anthelminthischen Eigenschaften einiger ozonisierter Ölsäureester an Hunden untersuchten, die mit Ascariden infiziert waren.

Die Erlanger Forschungsgruppe war daran interessiert, den Einfluss von ozonisierten ungesättigten Fettsäuren an menschlichen Zellen aufzuzeigen, vor allem an HL60Zellen (menschlichen Leukämiezellen) und in Anlehnung an die mögliche äusserliche Anwendung an A431-Zellen (menschlichen Hautkrebszellen) und NHDF-Zellen (menschlichen Hautfibroblasten).

Mit unterschiedlichen Messverfahren (Flow Cytometry, Quantifizierung fragmentierter DNA) wurde nachgewiesen, dass die Abnahme der Zelldichte von HL60 in den Wachstumsversuchen durch Induktion von Apoptose ausgelöst wird. In Hinblick auf eine medizinische Anwendung der Ozonide gegen beispielsweise Candida albicans oder Trichophyton spec. wäre das wünschenswert, da abgestorbene Zellen im Gegensatz zu nekrotischen Zellen ohne Entzündungsreaktion beseitigt werden können. Es müsste auch der Frage nachgegangen werden, ob normale Blutleukozyten eventuell weniger empfindlich auf Ozonide reagieren. In Versuchen wurde festgestellt, dass Hautzellen im Vergleich zu den Leukämiezellen wesentlich unsensibler gegenüber Ozoniden sind, wobei die transformierten A431-Zellen etwas stärker auf die Ozonide ansprachen als die NHDFZellen. Das unterstützt Berichte, nach denen eine äusserliche Anwendung von Ozoniden sehr gut verträglich ist.

Die Versuche mit Schutzstoffen gegen Sauerstoffradikale (sogenannte Scavenger) ergaben, dass 2,5-Dihydroxybenzoesäure in einer Konzentration von $0,2 \mathrm{mM}$ effektiv Apoptose verhindert, was für eine Beteili- gung von Reaktiven Sauerstoffspezies (ROS) spricht. Versuche, diese nachzuweisen, sind in Arbeit.

Der Mechanismus der durch Ozonide ausgelösten Reaktionen ist noch lange nicht entschlüsselt und erfordert weitgehende Erforschungen. Wie aus der Literatur ersichtlich ist, wirken Ozonide aus Pflanzenölen gegen eine Vielzahl von Bakterien und Pilzen keimtötend. Sie würden eine gute Alternative zu den üblichen Antibiotika geben, die bekanntermassen leicht Resistenzen auslösen können.

\section{Literatur}

1 Harada T: Chem Abstr 1934;28:4487.

2 Stevens FA: J Bact 1936;32:47.

3 Sharlit H: The use of ozonides in dermatology. NY State J Med 1946;46:2147-2149.

4 Butz LW: La Lande WA: J Am Pharmacol Assoc 1937;26:114.

\section{Nachrichten aus der Stiftung}

Vom 9. bis 11. September 1999 fand auf der Reisensburg bei Günzburg/Donau das elfte Projektleitersymposium der Carstens-Stiftung statt. Während der Tagung wurden die aktuellen Förderprojekte der Stiftung vorgestellt und diskutiert.

Zum dritten Mal wurde zu Beginn des Symposiums der Förderpreis der CarstensStiftung verliehen. Ausgezeichnet wurde Herr Dr. Roeland van Wijk für die herausragenden Ergebnisse seines langjährigen Forschungsschwerpunktes «The Similia Principle in Surviving Stress», die ein neuartiges Verständnis des Simile-Prinzips auf naturwissenschaftlicher Basis ermöglichen.

Der Preis ist mit 10000,-DM dotiert und wird für die weitere Forschung eingesetzt. 